\title{
Using hierarchical information integration to model consumer responses to possible planning actions : recreation destination choice illustration
}

\section{Citation for published version (APA):}

Louviere, J. J., \& Timmermans, H. J. P. (1990). Using hierarchical information integration to model consumer responses to possible planning actions : recreation destination choice illustration. Environment and Planning $A$, 22(3), 291-308. https://doi.org/10.1068/a220291

DOI:

10.1068/a220291

Document status and date:

Published: 01/01/1990

\section{Document Version:}

Publisher's PDF, also known as Version of Record (includes final page, issue and volume numbers)

\section{Please check the document version of this publication:}

- A submitted manuscript is the version of the article upon submission and before peer-review. There can be important differences between the submitted version and the official published version of record. People interested in the research are advised to contact the author for the final version of the publication, or visit the DOI to the publisher's website.

- The final author version and the galley proof are versions of the publication after peer review.

- The final published version features the final layout of the paper including the volume, issue and page numbers.

Link to publication

\footnotetext{
General rights

- You may freely distribute the URL identifying the publication in the public portal. follow below link for the End User Agreement:

www.tue.nl/taverne

\section{Take down policy}

If you believe that this document breaches copyright please contact us at:

openaccess@tue.nl

providing details and we will investigate your claim.
}

Copyright and moral rights for the publications made accessible in the public portal are retained by the authors and/or other copyright owners and it is a condition of accessing publications that users recognise and abide by the legal requirements associated with these rights.

- Users may download and print one copy of any publication from the public portal for the purpose of private study or research.

- You may not further distribute the material or use it for any profit-making activity or commercial gain

If the publication is distributed under the terms of Article $25 \mathrm{fa}$ of the Dutch Copyright Act, indicated by the "Taverne" license above, please 


\title{
Using hierarchical information integration to model consumer responses to possible planning actions: recreation destination choice illustration
}

\author{
J J Louviere \\ Faculty of Business, University of Alberta, Edmonton, Alberta, Canada \\ H J P Timmermans \\ Department of Architecture, Building and Planning, University of Technology, Eindhoven, \\ The Netherlands \\ Received 26 July 1988; in revised form 23 January 1989
}

\begin{abstract}
This paper outlines a study of recreational preferences designed to assess the usefulness of the method of hierarchical information integration for the study of complex decisionmaking processes which involve many potentially influential attributes. We assume that individuals who face complex decision problems initially group or classify influential attributes into subsets called decision constructs; then they rank these decision constructs into some overall preference for or choice among competing opportunities. To implement this conceptualization of individuals' cognitive processes we first measure overall preferences for recreational choice alternatives by creating separate experimental designs to study how individuals define each decision construct. Next we develop a design to integrate the decision constructs themselves so that we can observe how individuals' choices among, or preferences for, recreational opportunities change as we change how good an opportunity is with respect to each decision construct. The results of the study suggest that hierarchical information integration may be a potentially useful method to study complex decisionmaking problems of interest to planners and policy makers. Some avenues for further research are discussed.
\end{abstract}

Substantively, our results indicate that natural environment and accessibility, and maintenance have the most influence on the Eindhoven sample's preferences for and choices among parks. Some heterogeneity in preferences is also observed.

\section{Introduction}

Applications of laboratory-based preference and choice simulation methods such as policy-capturing, conjoint analysis and functional measurement to recreational destination choice problems have steadily increased since their introduction by Louviere (1974). Indeed, several recent recreational choice studies have applied so-called 'stated preference' techniques to explain individuals' preferences for recreational opportunities (for example, Allton, 1981; Cürry et al, 1983; Lieber and Fesenmaier, 1984; 1985; Lieber et al, 1988; Louviere and Woodworth, 1985; Timmermans, 1987). Stated preference models differ from revealed behavior gravity-type models and discrete choice models (for example, Baxter, 1981; Peterson et al, 1982; 1983; Stynes and Peterson, 1984), in that models are estimated from individuals' choices of experimentally designed (multiattribute), hypothetical choice alternatives rather than observations of actual choices.

Thus, this approach is someties called 'stated preference', or choice analysis because respondents are typically requested to express preferences for sets of hypothetical choice alternatives constructed according to experimental design principles. These 'stated' individual preferences or choices are decomposed statistically into the part-utilities associated with various levels of locational and nonlocational attributes varied in the experiments. Both revealed preference and stated preference approaches are based upon the assumption that prior to choice, individuals form multiattribute preference or decision functions which integrate the 
many factors that describe choice options into a single overall preference or utility vector. Details of the stated preference or choice approach and examples of applications in different areas of urban and regional analysis can be found in Bates (1988), Louviere (1988), Louviere and Timmermans (1987), Moore (1988), and Timmermans (1984a).

The main advantages of stated preference studies based on experimental design methods are their ability to (a) study decisionmaking and choice processes under controlled conditions, (b) create choice alternatives outside of the domain of experience and (c) minimize interattribute correlations. Because such experiments often deal with hypothetical and not real choice alternatives, one needs to demonstrate that decisionmaking and choice processes in hypothetical situations correspond to the same processes in real markets. Fortunately, previous research has indicated that models derived from stated preference or choice studies can predict real-world choice behavior accurately in a variety of contexts such as mode choice, choice of shopping center, and product choice (for example, Louviere and Meyer, 1981; Louviere and Wilson, 1978; Meyer et al, 1978; Timmermans, 1982; Timmermans and van der Heijden, 1984; 1986; Timmermans et al, 1984).

Indeed, the cited research studies indicate that the predictive ability of laboratory-based simulation methods is no worse, and may be better, than that of models estimated from revealed behavior data (for example, Lerman and Louviere, 1979; Louviere et al, 1981; Timmermans, 1984b). Also, both temporal stability (Malhotra,1982) and the spatial transferability of preference functions estimated on the basis of experimental design data has been shown to be satisfactory (van der Heijden and Timmermans, 1988). Such results are encouraging evidence that stated preference or choice studies can be potentially valuable tools for understanding and predicting spatial choice behavior in a variety of application contexts including recreational choice behavior.

This is not to say that the application of stated preference methods is always straightforward. For example, much previous research has been limited by an inability to handle large numbers of potentially influential decision attributes. This limitation arises because the size of experiments required to vary many levels of a few attributes or many attributes with a few levels increases exponentially with either the number of attributes, or the number of levels, or both. One can block an experiment into separate statistical subdesigns and randomly assign subjects into the blocks; however, blocking prevents the separate estimation of models for single subjects, and requires one to aggregate the responses of individuals. Consequently, many researchers prefer to incorporate no more than five to ten attributes in stated preference studies because either tasks become too large, or one foregoes models for single subjects, or one must aggregate over subjects forcing one to make assumptions about interindividual utility comparisons.

Thus, in many previous studies the total number of attributes studied has been arbitrarily limited to only a few. For example, Lieber and Fesenmaier (1984) investigated the effects of five attributes, and Timmermans (1987) the effects of ten. Excluding potentially significant attributes may bias estimates of utilities, reduce predictive validity, and/or lower the usefulness of results, because managers or planners may be interested in assessing the impact of additional (omitted) attributes. Thus, an approach to studying decisionmaking and choice behavior that retains the advantages of controlled experimentation and model estimation for single subjects, but also incorporates a large number of attributes would represent a potentially important extension of existing stated preference or choice methods.

Recently, Louviere (1984) proposed an approach which handles multiattribute choice tasks, called hierarchical information integration. The purpose of this paper 
is to describe hierarchical information integration and its application to recreational planning problems by illustrating its use in forecasting the choice of recreation areas by individuals, in response to changes in a variety of managerially interesting variables.

To accomplish these purposes, this paper is organized as follows. First, we outline the basic assumptions underlying hierarchical information integration. This is followed by a description of the empirical application, including details of the study design and the study area. Next, we describe the results of the study, and, last, we discuss the implications of the results of this study for future research in spatial choice analysis.

\section{Hierarchical information integration}

Hierarchical information integration (HII) is an extension of information integration theory. (Anderson, 1974; 1981; 1982). HII contains the assumption that when individuals are confronted with complex decision problems, they initially divide sets of attributes that influence their choice behavior into a smaller number, that is, into subsets, then evaluate each subset separately and aggregate their evaluations of each subset to choose between competing opportunities. For example, in recreational choice individuals may first separately evaluate attributes representing the natural environment of a park, its available facilities and activities, and its accessibility. Having made these separate evaluations, HII assumes that individuals integrate these separate evaluations to form preferences for competing recreational choice options.

For choice behavior to be represented by the process of HII several assumptions must be satisfied:

\section{Assumption 1}

Any particular choice behavior is influenced by a set of attributes, which may be quantitative or qualitative in nature. Let the total number of influential attributes be $N$.

\section{Assumption 2}

Faced with a complex decisionmaking problem, individuals group a set of influential attributes into subsets, which we term 'decision constructs'. Let the set of $N$ total attributes be divided into $I$ subsets. Let these subsets of decision attributes be denoted by $G_{i}(i=1, \ldots, I)$. For each subset, there is a set of $\left\{V_{i 1}, \ldots, V_{i n}\right\}$ attributes that represents the subset or decision construct.

\section{Assumption 3}

Associated with each attribute level is a part-worth utility, the value of which is revealed by the choices or judgments made by the individuals in response to variations in the experimentally manipulated attribute levels.

\section{Assumption 4}

In each of the $G_{i}$ subsets, individuals make judgments by integrating their part-worth utilities defined on the levels of the set of attributes contained in a particular subset $G_{i}$. The integration process follows some combination rule that may differ in each subset, but can be approximated by a statistical model with linear parameters and attributes. Thus, each subset $G_{i}$ is defined by some combination rule $\mathrm{g}_{i}$.

\section{Assumption 5}

Individuals respond to experimentally designed combinations of the levels of the attributes corresponding to the $i$ th subset $G_{i}$. The experimenter records these responses on some psychological measurement scale that represents a transformation 
of the true, but unknown, utilities of the levels of the attributes contained in the $i$ th subset. Let the $i$ th set of attributes, $G_{i}$, map onto decision-construct dimension $A_{i}$. Hence,

$$
\begin{aligned}
A_{i} & =\mathrm{g}_{i}\left(G_{i}\right) \\
& =\mathrm{g}_{i}\left(V_{i 1}, \ldots, V_{i n}\right) .
\end{aligned}
$$

Let $\left\{A_{i}\right\}$ be the decision constructs and their associated levels defined for the $i$ th subset of attributes.

\section{Assumption 6}

Individual choices among, or judgments about, combinations of levels of decision construct $A_{i}$ are observed on a psychological measurement scale, $R$, in an experimental setting. These responses can be decomposed into part-worth utilities for each level of each decision construct by means of some mapping, $f$. This mapping, $f$, can be expressed as a statistical model which is linear in its parameters and variables as follows:

$$
R=\mathrm{f}\left(A_{i}\right), \quad i=1, \ldots, I .
$$

Hence

$$
R=\mathrm{f}\left[\mathrm{g}_{i}\left(V_{i 1}, \ldots, V_{i n}\right)\right], \quad i=1, \ldots, I .
$$

\section{Assumption 7}

The overall judgment or choice response in the experiment, $R$, is related to the actual choice behavior of the individual in a real market, $B$, by means of some statistical specification:

$$
B=\mathrm{h}(R) \text {. }
$$

For modelling purposes this equation is too general. To apply the method of $\mathrm{HII}$ one has to specify $\mathrm{f}, \mathrm{g}_{i}$, and $\mathrm{h}$. There are a number of possible specifications that might represent the various combination rules, $\mathrm{g}_{i}$, and the overall mapping, $\mathrm{f}$. For example, if the $A_{i}$ and $R$ are recorded on category rating-scales, the $\mathrm{g}_{i}$ and $\mathrm{f}$ might be approximated by ordinary least squares (OLS) statistical models in which parameters and variables are linear; $h$ might be approximated by a logit or probit model. If, on the other hand, $R$ represents a choice among various $A_{i}$ combinations, then $f$ might also be represented as a logit model with linear parameters and variables. Thus, appropriate specifications for HII experiments are determined by the type of experiment and response scale, and the use to which one wishes to put the results.

A useful and usually. rather robust specification is the additive one. Adopting additive specifications, an application of HII would then involve the following steps (recall that the basic idea is to structure a decision task in such a way to allow one to study and analyze each of these integration processes separately):

(1) Cluster attributes into $\bar{I}$ sets based on logic, empirical evidence, or theory. Each set represents a different decision construct.

(2) Separate experimental designs are constructed for each of the $I$ sets identified in step (1), to create alternative descriptions defined by various combinations of levels, positions, or degrees of the variables that define the decision constructs represented by each set. Individuals evaluate combinations of the attribute levels, or positions in each construct set, on a category rating scale (or other suitable scale) that defines 'how much' of the construct is defined by each combination of attribute levels. 
(3) The response data obtained in step (2) are analyzed separately for each set (and for each individual in each set) to develop statistical models that describe how the different attributes combine to define each decision construct. For example, one might use multiple linear regression models to develop the statistical descriptions, but any statistical model that preserves the nature of the category response scale can be used, for example, a two-limit tobit model.

(4) Each higher-order decision construct is then treated as a factor whose levels are the numerical categories of the rating scales used to define the constructs in step (2). For example, one might select the categories 2,5 , and 8 from a ten-category scale to be the levels, and construct a fraction of a $3^{I}$ design ( $I$ is the total number of decision constructs). Individuals are told that the ratings reflect those that they gave to each decision construct in step (2). Therefore a subject's task is to evaluate the combinations of decision-construct ratings by ordering them on a new and different rating scale, or by expressing a choice among two or more combinations of decision-construct ratings.

(5) Ratings data obtained in step (4) are treated as measures of the individuals' overall utility which are subject to the normal error assumptions of the multiple linear regression or related general linear models (for example, ANOVA). If qualitative choice data have been obtained in step (4), one of several possible limited dependent variable models such as binary or multinomial, probit models or logit models can be used to analyze the data. In this way a statistical model of the integration of the decision-construct ratings can be derived.

(6) The separate statistical models estimated in steps (3) and (5) can be concatenated if one assumes that each decision process has a separate error distribution with expectation 0 , which is not correlated with the error distributions of the other decision processes.

Previously the method of hierarchical information integration has been applied to telecommunications and supermarket options (Louviere, 1984; Louviere and Gaeth, 1987). In a study of supermarket evaluations, Louviere and Gaeth found that utilities predicted by a hierarchical model were monotonically related to utilities observed for supermarket descriptions based on simultaneous presentation of information about all attributes (known as a 'full profile' task). Their results, although promising, suggest that additional research is needed to appreciate more fully the advantages and limitations of the method. In the present study the question of the applicability of hierarchical information integration for studying spatial choice behavior is addressed. In particular, in the next section we describe the empirical application of HII to the case of individual choice among competing parks in a particular area of The Netherlands.

\section{An application to recreation destination choice}

Sample and study area

The sample consists of 364 residents of the Eindhoven region, The Netheriands, who were interviewed during the summer of 1986 . The sample is a spatially stratified random sample, representative of households with telephones. Respondents were initially contacted by telephone and asked questions about their recreational activities. Following these questions, they were asked to participate in a more elaborate in-home interview. Those who agreed were interviewed personally by trained interviewers about a variety of issues related to their recreational choice behavior. In the present paper we deal only with the data obtained from the HII tasks completed by the subjects. 
Research approach

In order to explain individuals' preferences among alternatives such as recreational opportunities, one must first identify attributes of rereational choice alternatives that influence choice. Most previous recreational choice research was conducted in the United States, and it was unclear whether attributes found to influence recreators' choices in the USA could be generally applied to The Netherlands. In any case, previous US research suggested that recreational choice was influenced by many attributes (for example, Allton and Lieber, 1983; Knopp, 1972). So, we conducted pilot studies to provide insights into possible differences between US and Dutch behavior. These pilot studies generally confirmed that many attributes influence choice, and that US attributes also apply in The Netherlands.

In order to identify as complete a set of recreational choice attributes as possible, the pilot studies used a variety of procedures to derive candidate lists of influential attributes. Procedures used included factor listing, repertory grids, decision nets, and rating scales (van der Heijden et al, 1987; Timmermans and van der Heijden, 1987). This variety of methods was needed to determine whether previous findings were influenced by study methods, regional differences or both. Similar results were obtained using all methods; hence, nineteen attributes were retained for study. The appendix provides a list of these attributes and their levels used in the HII study.

As outlined in the section which discussed the HII method, the nineteen attributes were grouped into four subsets or decision constructs: (1) natural environment and accessibility, (2) facilities and activities, (3) maintenance, and (4) social use. Separate experimental designs were constructed to define each of the four decision constructs. Henceforth, we will refer to these separate designs as 'subdesigns'. In addition, a fifth experimental design (the 'overall' design) was created to measure the part-worth utilities of the four decision constructs. Random assignment was used to allocate individuals to one of the four subdesigns. In addition, each individual responded to four randomly selected treatments from the other three subdesigns, to insure that they understood the overall task and to improve its reliability. After evaluating the subdesign descriptions, respondents were randomly assigned to one of the two versions of the overall design: a preference rating task, or a choice task. In the present paper we consider only the data from the preference task. The order of the treatments was randomized between respondents for all tasks. Before evaluating the attribute descriptions in each subdesign, respondents studied the attributes and levels that were varied.

All subdesign evaluation tasks had the same general form: respondents saw a number of hypothetical parks described by combinations of levels of the attributes that defined a particular decision construct. Thus, each subdesign contained descriptions of different combinations of attributes. Subjects read a description of each park and made the following decisions: "how good is the natural environment and accessibility?", "how good are the facilities or activities?", "how good is the maintenance?", and "how good is the mix of types of people or social use?". In the overall task subjects evaluated combinations that described ratings which could have been given to the attribute combinations in the four separate subdesigns.

Subjects rated their degree of preference for visiting each of the hypothetical parks that were described, by a combination of ratings of the four separate decision constructs. In the next section we describe each of the subdesigns and the overall design used to study individuals' preferences for park alternatives.

Natural environment and accessibility subdesign The 'natural environment and accessibility' decision construct was represented by the following variables: (1) type 
of terrain, (2) vegetation density, (3) water features, (4) distance, and (5) entry fee. Each of these variables had four levels, except 'type of terrain', which had two levels. A main-effects, fractional factorial design consisting of sixteen combinations of attribute levels was constructed to study how individuals defined 'how good' the natural environment and accessibility of a park was. Each of the sixteen combinations of levels of the five attributes was printed on an index card." Respondents first sorted the sixteen index cards into three ordered categories of preference, and then ranked the cards within each category from most preferred to least preferred. Next, they were asked whether they were satisfied with the resulting rank orders; if not satisfied, they could rearrange the orders. Finally, respondents rated the sixteen combinations on an eleven-category rating scale ranging from 'extremely bad' $(0)$ to 'excellent' (10). The ranking task was used to familiarize respondents with the attributes and their levels, and to insure, as far as possible, that respondents would use the rating scale in an equal-interval manner. Ơnly. these rating data were used in the analyses reported in this paper.

Facilities and activities subdesign Previous research suggested individuals' preferences for recreation areas were influenced by the facilities and activities available in each area. Therefore, a seond subdesign was developed, to study how seven different facilities and activities affect recreational preferences: (1) boating, (2) fishing, (3) swimming, (4) hiking, (5) athletics, (6) camping, and (7) playgrounds. Because each activity is either available or not available in a recreation area, there are $2^{7}$ possible combinations of activities. Sixteen combinations of these variables were constructed to vary the presence or absence of these facilities and activities based on a main effects, fractional factorial design. Respondents rated each of the sixteen descriptions according to 'how good' they thought the facilities and activities were, using the same measurement procedure described for the natural environment and accessibility subdesign. Thus, respondents sorted the sixteen descriptions into three ordered categories, gave a strict rank ordering, and then rated each description on an eleven-category rating scale, the limits of which were defined as 'extremely bad' (0) and 'excellent' (10).

Maintenance subdesign The third decision construct was maintenance, which was represented by four variables: (1) maintenance of rest rooms, (2) maintenance of garbage cans and/or dumpsters, (3) maintenance of picnic, playground and shelter equipment, and (4) maintenance of grass, lawns, and trails. Each of these four variables was assigned two levels: seldom or not maintained, or regularly maintained. A full factorial design of these attribute levels requires $2^{4}(=16)$ descriptions. Because this is a relatively small design, we used the full factorial design to define this construct. Again, respondents sorted and ranked the descriptions, and rated them on a $0-10$ category rating scale.

Social use subdesign This decision construct was represented by three attributes: (1) age distribution and race of visitors, (2) crowding or privacy, and (3) patrols. The first two attributes had four levels, and 'patrols' had two levels. A half fraction of the $2 \times 4^{2}$-factorial design was developed to create combinations of these attribute levels. The measurement of respondents' preference ratings was identical to that used for the other subdesigns.

Overall design In order to link the rating responses for the descriptions in each subdesign to an individual's overall preference ratings, respondents rated the degree of preference for hypothetical park descriptions that were combinations of ratings levels of the four decision constructs that they had already generated in the subdesigns. That is, the four decision constructs (1) 'natural environment and 
accessibility', (2) 'facilities and activities', (3) 'maintenance', and (4) 'social use', were each treated as factors, whose levels were ratings made on the scales used in the subdesigns from the 0-10 category scale employed in each subdesign (four levels: $2,4,6$, and 8 ). These ratings levels were used to create combinations of decision constructs defined in terms of a respondents' own ratings.

A main-effects, fractional factorial design consisting of sixteen attribute combinations was developed to vary the four ratings levels of the four decision constructs. Respondents were asked to express their degree of preference for each of the sixteen combinations of hypothetical ratings levels of the four decision constructs, on a 0-100 millimeter line scale. They were instructed to assume that the numerical rating scores for each of the four decision constructs represented their own ratings, based on the variables used in the subdesigns. Respondents made a mark across the line scale at the point which best expressed their degree of preference for each hypothetical recreation area described. Ratings were recorded to the nearest millimeter and treated as interval-level data as in Louviere (1984) and Louviere and Gaeth (1987).

\section{Analysis and results}

The experimental tasks for each subdesign and the overall design generated both rank order and rating responses for each attribute description. Only the ratings data were used in subsequent analyses; the ranking task was used to encourage respondents to learn the descriptions, and to make their ratings more reliable. The effect of the levels of each attribute on a respondent's preference-rating was estimated separately for each subdesign and for the overall design. Although other analytical techniques can be used (for example, Louviere, 1988; Timmermans, 1984a), ordinary least squares (OLS) regression analysis was employed to estimate the effects of the attribute levels on each respondent's ratings. OLS regression analysis was used to estimate the part-worth utility parameters because we assumed that the response data were cardinal in measurement level and satisfied the error assumptions discussed earlier.

It has sometimes been argued that the interval-level measurement assumption is too strong, and that respondents find it easier to place alternatives in order of preference than to express a degree of preference (for example, Green and Srinivasan, 1978). It could also be argued that in ranking a set of profiles, subjects compare each alternative with all of the others; hence, the reliability of ranking responses is better than that of rating responses. Yet there is considerable empirical evidence to indicate that both ranking and rating tasks yield very similar results (for example, Green and Srinivasan, 1978; Rankin and Grube, 1980; Veldhuisen and Timmermans, 1984); for example, Anderson $(1981 ; 1982)$ provides a large amount of evidence, from many different areas of information processing to support the interval level-measurement assumption.

Unfortunately, rank=order methods lack an error theory, which means that one cannot perform statistical tests on competing model specifications. Moreover, the goodness of fit tests associated with rank-order methods are generally weak, especially if preference is monotonically related to the ordering of the attribute levels. Indeed, any monotonically consistent transformation of the data will produce equally good results, which implies that one cannot decide between an almost infinite number of competing models. Last, in many applications subjects can use rating scales in an equal-interval manner, provided that the experiment is properly designed and administered, including appropriate instructions for the use of the rating scale (for example, Louviere, 1988). Thus, unless there is evidence to 
the contrary, we recommend the use of rating scales in information integration tasks which measure degrees of preference for attribute profiles.

Additional main-effects-only statistical models were estimated from all designs for each respondent, by means of OLS regression techniques. Of course, some interaction effects may have been significant. If one wishes to test for such effects, one needs to construct designs that allow the estimation of interaction effects. Often, however, such designs involve many more attribute descriptions, which greatly increases the size of the task and cognitive demands, and may therefore decrease the reliability of the responses. One can compromise by using designs that protect the main effects from as much bias due to omitted effects as possible (for example, Louviere, 1988). This was the design strategy used where possible in this study. Significance of effects was tested by calculating the mean parameter and its associated standard error across all individuals who responded to a particular design. Separate $t$-tests were performed on each regression effect for each subdesign and the overall design. These results subdesign and the overall design are presented separately in tables $1,2,3,4$, and 5. In addition, the goodness of fit of the model was evaluated by means of Pearson's product-moment correlation coefficient. As one would expect, the results were good for all subdesigns and the overall designs. The mean correlation coefficients ranged between 0.91 and 0.99 , while the associated standard deviations varied between 0.02 and 0.09 . Of course, such results are expected because the models use a relatively large number of parameters to describe the preference ratings. Hence, we will not report detailed goodness of fit statistics.

Results for the natural environment and accessibility subdesign

This subdesign was administered to 108 respondents. The mean parameters and their standard errors are given in table 1 . As expected, results indicate that utilities decrease almost linearly as a function of increasing travel time; utilities also decrease, but at an increasing rate with increasing entry fee. From table 1 it

Table 1. Mean parameters and $t$-tests for 'natural environment and accessibility' subdesign.

\begin{tabular}{|c|c|c|c|}
\hline $\begin{array}{l}\text { Attribute and } \\
\text { attribute level }\end{array}$ & $\begin{array}{l}\text { Mean } \\
\text { parameter }\end{array}$ & $\begin{array}{l}\text { Standard } \\
\text { error }\end{array}$ & $t$ \\
\hline $\begin{array}{l}\text { Vegetation density } \\
\text { mixed } \\
\text { shrubs and bushes } \\
\text { wooded }\end{array}$ & $\begin{array}{r}0.02 \\
-0.02 \\
0.08\end{array}$ & $\begin{array}{l}0.04 \\
0.03 \\
0.03\end{array}$ & $\begin{array}{r}0.51 \\
-0.58 \\
1.46\end{array}$ \\
\hline $\begin{array}{l}\text { Water bodies } \\
\text { large creek } \\
\text { small lake } \\
\text { large lake }\end{array}$ & $\begin{array}{r}-0.27 \\
0.29 \\
-0.10\end{array}$ & $\begin{array}{l}0.06 \\
0.06 \\
0.07\end{array}$ & $\begin{array}{r}-4.84 \\
5.20 \\
-1.44\end{array}$ \\
\hline $\begin{array}{l}\text { Distance (in minutes) } \\
30-40 \\
50-60 \\
70-80\end{array}$ & $\begin{array}{r}0.35 \\
-0.30 \\
-0.89\end{array}$ & $\begin{array}{l}0.05 \\
0.05 \\
0.08\end{array}$ & $\begin{array}{r}6.74 \\
-6.11 \\
-10.88\end{array}$ \\
\hline $\begin{array}{l}\text { Entry fee (in florins) } \\
\text { f3.50 } \\
\text { f } 7.50 \\
\text { f12.50 }\end{array}$ & $\begin{array}{r}0.51 \\
-0.33 \\
-1.31\end{array}$ & $\begin{array}{l}0.05 \\
0.06 \\
0.10\end{array}$ & $\begin{array}{r}9.64 \\
-5.62 \\
-13.61\end{array}$ \\
\hline $\begin{array}{l}\text { Terrain } \\
\text { low hills }\end{array}$ & 0.04 & 0.02 & 1.60 \\
\hline
\end{tabular}


can be seen that, on average, respondents prefer (1) wooded areas, followed by (2) mixed areas of grassy fields and meadows, shrubs and bushes, with some woods, (3) predominantly shrubs covered areas, and (4) predominantly grassy and pasturetype areas. As far as water bodies are concerned, the results suggest that respondents prefer smaller water bodies. The difference in utilities between the levels of the terrain variable is not large; but respondents tend to prefer hilly terrain.

These results indicate that, on average, the respondents in this sample prefer hilly, predominantly wooded recreation areas, with small attractive lakes, close to their homes, with low entry fees. From table 1 it can be seen that most of the effects are significant, suggesting considerable agreement in respondents' evaluations of attributes of recreational opportunities. Only the effects associated with vegetation density were not statistically significant.

Because the attributes are orthogonal in a factorial design, the relative proportion of the variance explained by each attribute, adjusted for degrees of freedom, measures their relative effects. If all attributes have the same number of levels, the difference between the highest and the lowest utility value (the range of utilities) for each attribute is also a measure of relative attribute weight because the range will be related to the variance explained by each attribute. Thus, from table 1 it can be shown that, on average, entry fee and distance from home have the largest effect on respondents' ratings of natural environment and accessibility.

\section{Results for the facilities and activities subdesign}

The results of the analyses for this subdesign, which was administered to ninety-one respondents, are contained in table 2 , in which the mean parameter values, standard errors, and associated $t$-values are summarized. In general, availability of facilities increases respondents' utilities for recreation areas. In particular, the largest effects are for availability of hiking and swimming facilities, followed by boating, playground, and athletics facilities. Fishing and camping are considered less important. From table 2 it can also be shown that all effects are significant at conventional significance levels with the exception of camping and fishing.

Table 2. Mean parameters and $t$-tests for 'facilities and activities' subdesign.

\begin{tabular}{lllr}
\hline Attribute & $\begin{array}{l}\text { Mean } \\
\text { parameter }\end{array}$ & $\begin{array}{l}\text { Standard } \\
\text { error }\end{array}$ \\
\hline Boating & $0.28^{\circ}$ & 0.06 & 4.77 \\
Fishing & 0.07 & 0.06 & 1.15 \\
Hiking & 0.99 & 0.09 & 10.85 \\
Swimming & 0.65 & 0.08 & 7.95 \\
Athletics & 0.13 & 0.04 & 3.02 \\
Playing & 0.24 & 0.06 & 4.24 \\
Camping & 0.07 & 0.06 & 1.21 \\
\hline \hline
\end{tabular}

\section{Results for the maintenance subdesign}

This subdesign was administered to forty-eight respondents, and the analytical results are contained in table 3 . A study of table 3 reveals that the $t$-values associated with all effects are statistically significant (beyond the $5 \%$ alpha level). Thus, most respondents consider maintenance important, especially cleaning of rest rooms, provision of garbage cans and/or dumpsters, and maintenance of grass, lawns, and trails. 
Table 3. Mean parameters and $t$-tests for 'maintenance' subdesign.

\begin{tabular}{lllr}
\hline Attribute & $\begin{array}{l}\text { Mean } \\
\text { parameter }\end{array}$ & $\begin{array}{l}\text { Standard } \\
\text { error }\end{array}$ & $t$ \\
\hline Rest rooms & 1.09 & 0.08 & 13.98 \\
Garbage cans & 0.90 & 0.06 & 14.85 \\
Picnic equipment & 0.58 & 0.06 & 9.80 \\
Grass, lawns and trails & 0.88 & 0.09 & 9.68 \\
\hline
\end{tabular}

Results for the social use subdesign

This subdesign was administered to fifty-one respondents. The results of the analyses are contained in table 4 , which displays the mean parameter values and their

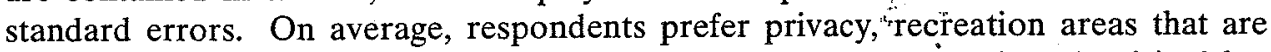
frequented by racially mixed visitors (compared to areas predominantly visited by caucasians), areas visited by families (compared with areas predominantly chosen by teenagers and young people), and areas that are regularly patrolled. A study of table 4 also reveals that 'crowding' has the largest effect on respondents' ratings for the 'social use' decision construct, closely followed by 'race and age distribution of the visitors'; regular patrols are less salient. The results contained in table 4 indicate that all effects are statistically significant beyond the $5 \%$ alpha level.

Table 4. Mean parameters and $t$-tests for 'social use' subdesign.

\begin{tabular}{lllr}
\hline $\begin{array}{l}\text { Attribute and } \\
\text { attribute levels }\end{array}$ & $\begin{array}{l}\text { Mean } \\
\text { parameter }\end{array}$ & $\begin{array}{l}\text { Standard } \\
\text { error }\end{array}$ & \\
\hline Crowding & & & \\
a bit of privacy & 0.87 & 0.13 & 6.54 \\
little privacy & -0.50 & 0.11 & -4.64 \\
no privacy & -1.86 & 0.17 & -10.80 \\
Age distribution/race & & & \\
raciaily mixed youngsters & 0.29 & 0.11 & 2.65 \\
white families & -0.32 & 0.11 & -2.79 \\
racially mixed families & 0.65 & 0.11 & 5.95 \\
Patrols & 0.24 & 0.06 & 4.28 \\
\hline
\end{tabular}

Table 5. Mean parameters and $t$-tests for 'overall' design.

\begin{tabular}{lclr}
\hline $\begin{array}{l}\text { Attribute and } \\
\text { attribute levels }\end{array}$ & $\begin{array}{l}\text { Mean } \\
\text { parameter }\end{array}$ & $\begin{array}{l}\text { Standard } \\
\text { error }\end{array}$ & \\
\hline $\begin{array}{l}\text { Natural environment and accessibility } \\
\text { linear }\end{array}$ & 6.84 & 0.35 & 19.67 \\
quadratic & 0.22 & 0.08 & 2.95 \\
Facilities and activities & 1.28 & 0.23 & 5.47 \\
linear & 0.32 & 0.07 & 4.51 \\
quadratic & & & \\
Maintenance & 2.64 & 0.26 & 10.05 \\
linear & 0.16 & 0.07 & 2.44 \\
quadratic & & & \\
Social use & 1.60 & 0.22 & 7.17 \\
linear & 0.14 & 0.06 & 2.24 \\
quadratic & & & \\
\hline
\end{tabular}




\section{Results for the overall design}

The overall design was administered to 118 respondents. The results are presented in table 5 , in which the mean parameter values and their standard errors are listed. Because the factor levels in this experiment are quantitative (values of the rating scales used in the subdesigns), orthogonal, polynomial, multiple linear-regression was used to estimate the main effects (part-worth utilities) for each subject. In table 5 it is shown that preferences for all four decision constructs increase along with increasing ratings for each decision construct: All linear and quadratic terms are significant and positive. From table 5 it-can also be shown that 'natural environment and accessibility' is the most important decision construct, followed by 'maintenance', 'social use', and 'facilities and activities', respectively.

\section{Conclusions and discussion}

In this paper we have introduced the method of $\mathrm{HII}$ and illustrated its potential applications to planning problems in a study of recreational preferences. HII was developed to handle complex multiattribute decisionmaking problems involving large numbers of attributes. HII is based on the assumption that individuals group attributes of particular decisionmaking tasks into subsets which represent higher order decision constructs, and then integrate the levels of these decision constructs into some overall preference or choice. HII requires analysts to develop experimental designs to study the separate evaluations of each decision construct and to integrate the subjective evaluations of the decision constructs into preferences or choices. In these decision experiments subjects rate planning alternatives on category scales, and these data are analyzed by conventional OLS regression methods commonly used to develop multiattribute utility models.

The main advantage of HII over conventional decompositional preference and choice methods, for (recreational) planning problems is that it allows a researcher to study many variables of managerial interest and also to predict the impact of such variables on consumer preference, or choice behavior. If one wants to study the effect of many variables on preference judgments, traditionally one would choose between a trade-off type of design (Knight and Menchik 1976), or a blocked fractional factorial design (Louviere 1988).

Trade-off designs are rarely used in practice (Cattin and Wittink 1986), and it is not obvious what assumptions respondents should make about attributes not included in a particular trade-off matrix. For example, if subjects make inferences about missing attributes (Johnson and Levin 1985), their responses might be systematically biased. In addition, trade-off designs do not allow one to estimate main and interaction effects simultaneously. In contrast, certain fractional factorial designs permit one to estimaterinteraction effects, but it is often infeasible to include a large number of attributes in practice because experimental tasks become too large. In such cases, blocked designs may be used, but this design strategy precludes the estimation of separate models for single subjects. Thus, the advantage of HII over traditional decompositional preference and choice models for planning purposes is their ability to estimate models for single subjects. This permits one to incorporate heterogeneity in the analyses, even if the number of attributes of managerial or planning interest is large.

Of course, this gain comes at a cost. For example, grouping attributes into subsets does not allow one to estimate interaction effects across those subsets. Whether this constitutes a serious problem in practice depends to a large degree on the predictive success of a less complex model and the structural validity of the research findings. Another potential loss is that one no longer has observations on 
the trade-offs between all influential attributes, which might have a negative effect on the reliability of the results.

Despite the limitations mentioned above, the results of the present study support the validity of the HII approach. The utilities estimated from each subdesign and the overall design were monotonically related to our expectations... Moreover, simple additive main-effects-only models seem to provide adequate approximations to the way in which respondents integrate the part-worth utilities for the levels of the various attributes to express their overall preferences. Also, the experimental tasks used were no more difficult than similar tasks which have been applied in many previous studies, in a variety of contexts (Cattin and Wittink, 1986; Green and Srinivasan, 1978; Louviere, 1988). If similar results can be obtained in other decision contexts of planning interest, it would encourage more researchers to have confidence in the applicability of the method of HII to the analysis of decisionmaking processes that involve a large number of attribute's. Ultimately, however, it is important to demonstrate that utility functions estimated from $\mathrm{HII}$ experiments can successfully predict real-world choice behavior. We plan to address this and related problems in future research.

Additional research is required to determine the limitations and domain of application of HII. In particular, previous research has shown that subjects use different decision heuristics as a function of the complexity of the decision task (for example, Billings and Marcus, 1983; Einhorn et al, 1979; Olshavsky, 1979; Payne, 1976; 1982; Russo and Dosher, 1983). Most, if not all, of these studies were concerned with problem solving and decisionmaking under experimental conditions. However, if such findings hold true for real-world decisions, it is important to determine whether hierarchically structured conjoint tasks can uncover complex decisionmaking processes, or whether subjects adopt different, artificial decision-strategies unrepresentative of their real-world decisionmaking processes. It is also important to determine how well simple utility functions (such as additive ones) estimated from a given design can represent complex decision heuristics.

Another important area for future research inquiry concerns the grouping of attributes into subsets. Parameters associated with particular attributes might be influenced by the type, number, and levels of the other attributes used in particular subdesigns. Hence, one needs to determine whether or not the grouping of the attributes into subsets has a significant impact on the results. Hierarchically structured tasks preclude the estimation of interaction effects between attributes in different subdesigns. Hence, it is important to determine whether this significantly affects results.

It would also be valuable to maximize the accuracy and the flexibility of the approach and the models derived from it. For example, rather than using simple additive models, one could use weight-shifting models (Eagle, 1984; 1988; Meyer
and Eagle, 1982) to determine preference shifts in one or more subdesigns. This would allow one to predict whether or not more weight will be given to attributes with higher variability. Furthermore, rather than using preference ratings in the overall design, one could ask individuals to make choices among two or more planning alternatives. The use of a discrete choice response would allow one to study, simultaneously, preference formation and choice processes. We hope to address this issue in the near future, based on the choice data we obtained as part of the study reported in this paper.

The substantive conclusions of this study are that, on average, respondents prefer well-maintained, predominantly wooded and hilly recreation areas with a small pond, located near to their homes, offering facilities for hiking or swimming at cheap entry fees, and frequented predominantly by racially-mixed visitors, mainly 
families with children. In terms of higher order decision constructs, 'natural environment and accessibility', and 'maintenance' have the most influence on respondents' preferences. These results imply that planners should place the most emphasis on designing recreational areas to cater for citizens' preferences. Of course, scenery may be difficult or impossible to change, and in any case, usually cannot be changed rapidly. However, recreation managers can easily manipulate entry fees and/or improve different aspects of maintenance, to produce positive changes in user judgments about recreational opportunities under their control. As far -as facilities are concerned, respondents prefer hiking and swimming, followed by boating and playgrounds. These facilities are under the direct control of recreation managers, hence these results provide a direct blueprint to follow to alter facilities, and thereby increase user satisfaction.

For example, the coefficients of the regression equations can be used in a straightforward way to identify the attributes of recreation areas that have the most effect on respondents' preferences. Predictions based on the preference equations can also be mapped into observed behavior, which would allow planners to anticipate the likely effect on use and visitation of changing the attributes of recreational areas. The statistical results could be optimized with respect to costs or other resource criteria, thereby permitting one to identify optimal planning strategies. We have not pursued these possibilities in this paper because we were interested primarily in increasing our experience with HII in a planning context, and we were less interested in deriving appropriate planning strategies. Additionally, the HII approach is similar in application to several commonly applied stated preference methods (for example, Lieber and Fesenmaier, 1984); hence, its applicability to planning problems should be comparable.

We have reported only aggregate results in this paper. Although such results provide an indication of average preferences, conflicting or unimodal preference distributions cannot be identified from aggregate data. Indeed, our results suggest that there is some heterogeneity in respondents' preferences for attributes of recreation areas. Therefore, it is important in future research to identify groups of respondents with significant differences in recreational preferences, in order to test for possible structural relationships with socioeconomic, or other important policyrelevant measures involving differing individual preferences. For example, it would be interesting to know whether segments can be found on the basis of the activities respondents prefer. "Identification of such segments would provide recreation managers and planners with additional information about segments and differences in recreation styles. It would also allow them to assess the likely consequences of offering different planning options to groups with different preferences.

Acknowledgements. The data for the present study were gathered in the context of a larger project, the aim of which is to develop a variety-seeking model of recreational choice behavior. Dr van der Heijden coordinated the data collection for this larger project, which was funded by The Netheriands Organization for Scientifíic Research (NWO/SRO). Prof. Timmemans gratefully acknowledges a travel grant from the same organization which allowed for a trip to Edmonton to prepare the present study.

\section{References}

Allton D J, 1981, "An experimental approach to modelling spatial choice in the urban recreation environment", unpublished doctoral dissertation, Department of Geography, Southern Illinois University, Carbondale, $\mathrm{IL}$

Allton D J, Lieber S R, 1983, "Attributes of Chicago trail areas" Leisure Sciences 5 197-220

Anderson N H, 1974, "Information integration theory: a brief survey", in Contemporary Developments in Mathematical Psychology Eds D Krantz, $R$ Atkinson, D Luce, P Suppes (W H Freeman, San Francisco, CA) pp 236-305 
Anderson N H, 1981 Foundations of Information Integration Theory (Academic Press, New York)

Anderson N H, 1982 Methods of Information Integration (Academic Press, New York)

Bates J J, 1988, "Stated preference techniques and the analysis of consumer choice", in Store Choice, Store Location and Market Analysis Ed. N Wrigley (Routledge, Chapman and Hall, Andover, Hants) pp 203-224

Baxter M J, 1981, "Models of recreational trip distribution" Regional Studies 15 327-344

Billings R, Marcus S, 1983, "Measures of compensatory and noncompensatory models of decision behaviour: process tracing versus policy capturing" Organizational Behaviour and Human Performance $31331-352$

Cattin P, Wittink D R, 1986, "Commercial-use of Conjoint Analysis: an update", presented at the ORSA/TIMS Marketing Science Meetings, Richardson, TX, 12-15 March; copy available from the author

Curry D J, Louviere J J, Rauch D, Woodworth G, 1983, "Recreation Destination Choice", Final Report 35, Institute of Urban and Regional Research, The University of Iowa, Oakdale, IA

Eagle T E, 1984, "Parameter instability in disaggregate retail choice models: experimental evidence" Journal of Retailing $60101-123$

Eagle T E, 1988, "Context effects in consumer spatial behaviour", in Behavioural Modelling Approaches in Geography and Planning Eds R G Golledge, H J P Timmermans (Croom Helm, Andover, Hants) pp 299-315

Einhorn H J, Kleinmutz D N, Kleinmutz B, 1979, "Linear regression and process-tracing models of judgment" Psychological Review 86 464-485

Green P E, Srinivasan V, 1978, "Conjoint analysis in consumer research: issues and outlook" Journal of Consumer Research 5 103-123

Heijden $R$ van der, Timmermans $H$ J P, 1988, "The spatial transferability of a decompositional multiattribute preference model" Environment and Planning $A$ 20 1013-1025

Heijden $R$ van der, Timmermans H J P, Malde A van, 1987, "Identificatie van factoren van invloed op openlucht recreatiegedrag (Identification of factors influencing outdoor recreational behaviour)" Recreatie en Toerisme 19 185-191

Johnson R D, Levin I P, 1985, "More than meets the eye: the effect of missing information on purchase evaluations" Journal of Consumer Research 12 169-177

Knight R L, Menchik M D, 1976, "Conjoint preference estimation for residential land use policy evaluation", in Spatial Choice and Spatial Behavior Eds R G Golledge, G Rushton (The Ohio State University Press, Columbus, OH) pp 135-156

Knopp T B, 1972, "Environmental determinants of recreation behaviour" Journal of Leisure Research 4 129-1381

Lerman S R, Louviere J J, 1979, "Using functional measurement to identify the form of utility functions in travel demand analysis" Transportation Research Record number 673, $78-86$

Lieber S R, Fesenmaier D R, 1984, "Modelling recreation choice: a case study of management alternatives in Chicago" Regional Studies 1831 - 43

Lieber S R, Fesenmaier D R, 1985, "Physical and social conditions affecting recreation site preferences" Environment and Planning $A$ 17 1613-1625

Lieber S R, Fesenmaier D R, Bristow R S, 1988, "Social and environmental characteristics affecting alternatives for outdoor recreation participation", in Behavioural Modelling Approaches in Geography and Planning Eds R G Golledge, H J P Timmermans (Croom Helm, Andover, Hants) pp 272-289

Louviere J J, 1974, "Predicting the response to real stimulus objects from an abstract evaluation of their attributes: the case of trout streams" Journal of Applied Psychology 59 274-283

Louviere J J, 1984, "Hierarchical information integration: a new method for the design and analysis of complex multiattribute judgment problems" in Advances in Consumer Research, Volume XI Ed. Th C Kinnear (Association for Consumer Research, Provo) pp 148-155

Louviere J J, 1988 Analyzing Decision Making: Metric Conjoint Analysis Quantitative Applications in the Social Sciences (Sage, London)

Louviere J J, Gaeth G J, 1987, "Decomposing the determinants of retail facility choice using the method of hierarchical information integration: a supermarket illustration" Journal of Retailing $6325-48$

Louviere J J, Meyer R, 1981, "A composite attitude-behaviour model of traveller decision making" Transportation Research $15411-420$ 
Louviere J J, Timmermans H J P, 1987, "A review of some recent advances in decompositional preference and choice models", paper presented at the Fifth Colloquium on Theoretical and Quantitative Geography, Bardonnecchia, Italy, 8-11 September; copy available from the author

Louviere J J, Wilson E, 1978, "Predicting consumer response in travel analysis" Transportation Planning and Technology $41-9$

Louviere J J, Woodworth G G, 1985, "Models of park choice derived from experimental and observational data: a case study in Johnson County, Iowa", research report, University of Iowa, IA

Louviere J J, Henley D H, Woodworth G, Meyer R J, Levin I P, Stoner J W, Curry D, Anderson D A, 1981, "Laboratory-simulation versus revealed preference methods for estimating travel demand models" Transportation Research Record number 794, 42-51

Malhotra N, 1982, "Structural reliability and stability of non-metric conjoint analysis" Journal of Marketing Research $19199-207$

Meyer R, Eagle T E, 1982, "Context-induced parameter instability in a disaggregate stochastic model of store choice" Journal of Marketing Research 19 61-71

Meyer R, Levin I, Louviere J, 1978, "Functional analysis of mode choice" Transportation Research Record number 673, 1-7

Moore L, 1988, "Stated preference analysis and new store location", in Store Choice, Store Location and Market Analysis Ed. N Wrigley (Routledge, Chapman and Hall, Andover, Hants) pp 203-224

Olshavsky R W, 1979, "Task complexity and contingent processing in decision making: a replication and extension" Organizational Behavior and Human Performance 24 300-316

Payne J W, 1976, "Task complexity and contingent processing in decision making: an information search and protocol analysis" Organizational Behavior and Human Performance $16366-387$

Payne J W, 1982, "Contingent decision behaviour" Psychological Bulletin $92382-402$

Peterson G L, Anderson D H, Lime D W, 1982, "Multiple use site demand analysis: an application to the BWCA wilderness" Journal of Leisure Research 14 27-36

Peterson G L, Dwyer J F, Darragh A, 1983, "A behavioural urban recreation site choice model" Leisure Sciences 6 61-81

Rankin W L, Grube L W, 1980, "A comparison of ranking and rating procedures for value system measurement" European Journal of Social Psychology 10 233-246

Russo J E, Dosher B A, 1983, "Strategies for multiattribute binary choice" Journal of Experimental Psychology 9 676-696

Stynes D J, Peterson G L, 1984, "A review of logit models with implications for modeling recreation choices" Journal of Leisure Research $16295-310$

Timmermans H J P, 1982, "Consumer choice of shopping centre: an information integration approach" Regional Studies $16171-182$

Timmermans H J P, 1984a, "Decompositional multiattribute preference models in spatial choice analysis" Progresss in Human Geography $8189-221$

Timmermans H J P, 1984b, "Discrete choice versus decompositional multiattribute preference models: a comparative analysis of model performance in the context of spatial shopping behaviour", in London Papers in Regional Science 14: Discrete Choice Models in Regional Science Ed. D E Pitfield (Pion, London) pp 88-101

Timmermans H J P, 1987, "Hybrid and non-hybrid evaluation models for predicting outdoor recreation behaviour: a test of predictive ability" Leisure Sciences 9 67-76

Timmermans H J P, Heijden R van der, 1984, "The predictive ability of alternative decision rules in decompositional multiattribute preference models" Sistemi Urbani 5 89-101

Timmermans H J P, Heijden R van der, 1986, "Retail change and individual choice dynamics: a conjoint based choice simulator experiment", in Commercial Change Eds A Metton, L Cassassas (Universidad de Barcelona, Barcelona) pp 413-446

Timmermans H J P, Heijden R van der, 1987, "Uncovering spatial decisionmaking processes: a decision net approach applied to recreational choice behaviour" Tijdschrift voor Economische en Sociale Geografie 78 297-305

Timmermans H J P, Heijden R van der, Westerveld H, 1984, "Decisionmaking between multiattribute choice alternatives: a model of spatial shopping-behaviour using conjoint measurements" Environment and Planning $A$ 16 377-387

Veldhuisen K J, Timmermans H J P, 1984, "Specification of individual residential utility functions: a comparative analysis of three measurement procedures" Environment and Planning A 16 1573-1582 


\section{APPENDIX}

\section{Higher order constructs, attributes and attribute levels}

Natural environment and accessibility

Attribute 1. Type of terrain

(a) predominantly flat with a few river bluffs and/or very low hills.

(b) mixture of low hills and/or river bluffs with flat areas.

Attribute 2. Vegetation density

(a) predominantly grassy -and pasture-like with-areas of shrubs and bushes and-a few wooded areas.

(b) mixed areas of grassy fields and meadows, shrubs, and bushes, with some woods.

(c) predominantly shrubs, bushes, and meadows, with șome grassy fields and meadows.

(d) predominantly wooded, with some shrubs and bushes.

Attribute 3. Water features

(a) small, attractive clear creek or brook that meanders through part of the site.

(b) relatively attractive large creek or small river that is a major reason people come here.

(c) small, attractive, man-made or natural, lake or pond that is located in one area of the site.

(d) large, attractive natural or man-made lake or reservoir that is a major reason people come here.

Attribute 4. Distance (in minutes)
(a) $10-15$
(b) $30-40$
(c) $50-60$
(d) $70-80$.

Attribute 5. Entry fee (in florins)
(a) f0.50
(b) $\mathrm{f} 3.50$
(c) $f 7.50$
(d) $\mathrm{f} 12.50$.

Facilities and activities

Attribute 6. Boating

(a) no (b) yes.

Attribute 7. Fishing

(a) no (b) yes.

Attribute 8. Hiking

(a) no (b) yes.

Attribute 9. Swimming

(a) no (b) yes.

Attribute 10. Athletic fields

(a) no (b) yes.

Attribute 11. Children's playgrounds

(a) no (b) yes.

Attribute 12. Camping facilities

(a) no (b) yes.

\section{Maintenance}

Attribute 13. Maintenance of rest rooms

(a) seldom or not at all (b) regularly.

Attribute 14. Maintenance of garbage cans and/or dumpsters

(a) seldom or not at all (b) regularly.

Attribute 15. Maintenance of picnic, playground and shelter equipment

(a) seldom or not at all (b) regularly.

Attribute 16. Maintenance of grass, lawns and trails

(a) seldom or not at all (b) regularly. 
Social use

Attribute 17. Age distribution

(a) predominantly white teenagers and young people.

(b) racially mixed, predominantly teenagers and young people.

(c) predominantiy white families with children.

(d) racially mixed, predominantly families with children.

Attribute 18. Crowding

(a) little traffic and few people around. There are several nice places to go if you wish some privacy and quiet.

(b) light traffic and some people around almost everywhere, but there are a few quieter areas where you can have a bit of privacy.

(c) moderate traffic congestion and crowding with quite a few people almost everywhere. There are some less noisy areas, but there is little privacy.

(d) very crowded and noisy with considerable traffic. Difficult to find places not already crowded. No privacy.

Attribute 19. Patrols

(a) seldom or not at all (b) regularly. 